\title{
Comparative Characteristic of the Lipid Profile in Residents of Different Regions of the Republic of Sakha (Yakutia)
}

\author{
Sardana Alekseeva ${ }^{1}$, Uliana Antipina ${ }^{1}$ and Sergei Protodyakonov ${ }^{2}$ \\ ${ }^{1}$ The Normal and pathological physiology Department of the Medical institute. North-East Federal University named \\ after M.K. Ammosov, Russia \\ ${ }^{2}$ M.K. Ammosov North-East Federal University, Russia \\ *Corresponding author. Email: srdn.alekseeva@s-vfu.ru
}

\begin{abstract}
The adaptation process in the Far North is accompanied by significant changes in the physiological systems of the organism. Malfunctions of regulatory systems significantly alter a person's ability to adapt to living conditions and cause serious metabolic disorders. The priority of modern medicine is timely diagnosis, treatment, and prevention of diseases in the population of the Republic. Thereby, great value is given to regional programs to improve the life quality of the republic's residents, considering territorial and ethnic characteristics in conditions of socio-economic development. Projects are being carried out for a multifactorial study of the health status of the indigenous and newcomer population in different regions of the Republic of Sakha (Yakutia). This work uses the research results of the lipid profile of residents of Tattinsky, Verkhnevilyuisky, Verkhoyansky and Eveno-Bytantaisky uluses. Changes in lipid metabolism and hormonal spectrum are known to cause serious diseases of the cardiovascular system, endocrine disorders, including the development of metabolic syndrome. Early diagnosis and competent interpretation of these changes, considering regional specifics, can significantly improve disease prevention, which is one of the priorities of modern medicine.
\end{abstract}

Keywords: lipid profile, living conditions, prevention, regions of the Republic of Sakha, Yakutia

\section{INTRODUCTION}

The Republic of Sakha (Yakutia) is the largest subject of the Russian Federation. The climatic features of Yakutia are determined by its geographical position in northeast Asia, winter powerful Siberian anticyclone, the free invasion of Arctic air, the distance from the Atlantic Ocean, the low availability of humid and warm masses from the east and south, as well as the complex relief and nature of the underlying surface. Yakutia has a sharply continental climate, the main characteristics of which are low winter and high summer temperatures, dryness and large fluctuations in both daily and seasonal temperatures, and a low amount of atmospheric precipitation, which falls mainly in summer. The interior region of Yakutia is characterized by a sharp temperature fluctuation in winter to summer [1].
To adapt a person in these conditions, the state of the nervous and endocrine systems of the body plays a large role, taking a direct part in the development of adaptation mechanisms and reaction stress in extreme climate. The process of adaptation in the far North is accompanied by significant restructuring of all its physiological systems. Disturbances in the work of the body's regulatory systems significantly change a person's ability to adapt to living conditions, causes severe metabolism disorders [2].

The priority task of modern medicine is the timely diagnosis, treatment and prevention of diseases in the population of the Republic. Great importance is attached to regional programs to improve the life quality of residents of the republic, taking into account territorial, ethnic characteristics in the conditions of modern socioeconomic development. These programmes carry out 
multifactorial health studies of indigenous and nonindigenous population in different regions of Yakutia.

In this work, the results of the study of the hormonal status and lipid profile of residents of Tattinsky, Verkhnevilyuisky, Verkhoyansky and EvenoBytantaysky uluses were used.

It is known that changes in lipid metabolism and hormonal spectrum of the body can cause severe diseases of the cardiovascular system, the development of endocrine pathology, including the development of metabolic syndrome. Early diagnosis and competent interpretation of these changes, can significantly improve the methods of preventing diseases, which is one of the priority tasks of modern medicine.

\section{PURPOSE OF THE STUDY}

The purpose of the work: to identify the features of lipid metabolism state in residents of central, western and northern regions of Yakutia.

To achieve this goal of the work, the following tasks are set:

1. Determine the features of the shift in lipid status.

2. Identify gender differences in changes in lipid status.

3. Conduct a comparative analysis of lipid profile indicators in residents of the central, western and northern regions of the Republic of Sakha (Yakutia)

\section{MATERIALS AND METHODS}

The study was carried out within the project "Multifactorial study of the health status of the indigenous and non-indigenous population of Yakutia to improve life quality of residents of the republic taking into account territorial, ethnic characteristics in modern socio-economic development."

Lipid spectrum data from the Database, created on the basis of the material during the expedition to 4 uluses (I) by employees of the medical institute and medical clinic of NEFU in 2017, were analyzed. The study was approved by the bioethics commission.

Blood was taken according to international rules using "Informed Consent" from residents of uluses undergoing an extended medical examination.

The number of persons surveyed was 534. Women 397 , men - 137. The age of the examined was from 21 to 65 years old. The main contingent surveyed is people of working age from 20 to 60 years old.

Blood was taken from the fasting ulnar vein after a 10-12-hour period of night fasting. The concentration of total cholesterol, very low, low and high density lipoproteins (LDL, LDL and HDL), serum triglycerides (TG) was determined by automatic analyzer, and the atherogenicity coefficient (CA) was calculated as the ratio (OxC $-\mathrm{xC} \mathrm{HDL}) /$ When judging the frequency of hypercholesterolemia in the study groups, the criterion was a change in the total cholesterol level above $5 \mathrm{mmol} / \mathrm{L}$

Statistical processing of the obtained data was carried out by Microsoft Office Excel and included analysis of the distribution of characteristics norm, determination of averages and their errors. The validity of the differences between the mean values of the measures was assessed by the Student's t-test and univariate variance analysis. Differences were considered statistically significant at $\mathrm{p}<0.05$.

\section{RESULTS AND DISCUSSION}

Triglycerides are a source of energy for the human body and a store of lipids in adipose tissue. They are formed in the liver, entering the blood in most cases with food, and transported in the form of various forms of lipids. In combination with cholesterol, phospholipids and apoproteins, it is part of very low density lipoproteins (VLDL).

For the adaptation of the human body in the conditions of the North, human nutrition plays an important role. Of particular importance for maintaining human health, efficiency and longevity is the full and regular provision of the body with all the necessary micronutrients, vitamins and minerals. The average daily energy value of the diet was $2516 \mathrm{kcal}$ for men, and $1887 \mathrm{kcal}$ for women. Men consumed an average of $82 \mathrm{~g}$ of protein per day, women $-57 \mathrm{~g}$. The average daily fat intake was $78.5 \mathrm{~g}$ and $56 \mathrm{~g}$ for men and women, respectively. The average carbohydrate intake per day for men is $370 \mathrm{~g}$, among women $-290 \mathrm{~g}$. Thus, in women, the average intake of proteins, fats, carbohydrates and the energy value of the diet is lower than the norm recommended by the SanPiN. In men, only the average fat intake is below the norm of physiological consumption.

Eating fatty foods (fatty meats and fish, smoked foods, high-fat dairy products, carbonated drinks, coffee, sweets, fast food) are known to increase blood triglyceride levels for ten to twelve hours. The reason for an increase in triglyceride levels may be the presence of a hereditary predisposition, genetic defects and concomitant chronic diseases (nephropathy, hormone imbalance, hypothyroidism, uncompensated diabetes mellitus, pancreatitis, metabolic syndrome, alcoholism, and others). An important factor in the development of hypertriglyceridemia may be taking medications, such as: oral contraceptives; diuretics: furosemide, veroshpiron; antiarrhythmic drugs cordaron; corticosteroids: prednisolone, dexamethasone and others). 
The analysis of the lipid blood profile in men and women of the Tattinsky, Verkhnevilyuysky, Verkhoyansky and Eveno-Bytantaysky uluses of the
Republic of Sakha (Yakutia) was carried out. The results are shown in Table 1.

Table 1. The lipid blood profile in residents of the uluses $(\mathrm{M} \pm \mathrm{m})$

\begin{tabular}{|l|l|l|l|l|}
\hline Lipids & Eveno-Bytantaysky & Tattinsky & Verkhoyansky & Verkhnevilyuysky \\
\hline TG & $1.19 \pm 0.1$ & $1.03 \pm 0.04$ & $1.22 \pm 0.2$ & $1.17 \pm 0.07$ \\
\hline Cholesterol & $5.35 \pm 0.1$ & $5.4 \pm 0.08$ & $6.76 \pm 1$ & $5.37 \pm 0.09$ \\
\hline HDL & $3.19 \pm 1.5$ & $3.25 \pm 1.32$ & $2.93 \pm 1.19$ & $1.45 \pm 0.04$ \\
\hline LDL & $2.72 \pm 0.07$ & $3.27 \pm 0.07$ & $2.83 \pm 0.08$ & $2.95 \pm 0.09$ \\
\hline VLDL & $0.54 \pm 0.05$ & $0.54 \pm 0.04$ & $0.46 \pm 0.02$ & $0.52 \pm 0.03$ \\
\hline KA & $2.34 \pm 0.1$ & $2.11 \pm 0.07$ & $3.4 \pm 0.09$ & $2.92 \pm 0.12$ \\
\hline
\end{tabular}

Indicators of triglycerides, cholesterol $(6.76 \pm 1.0$ $\mathrm{mmol} / \mathrm{l}$ ), atherogenic coefficient (3.4) in the blood are higher in residents of the Verkhoyansk ulus than in representatives of the studied uluses.

In women from all 4 regions, triglyceride (TG) levels remain within the normal range (Table 2).
The highest percentage of increases were in women of the Verkhnevilyuisky $(1.18 \pm 0.08 \mathrm{mmol} / \mathrm{l})$ and Verkhoyansky $(1.39 \pm 0.3 \mathrm{mmol} / \mathrm{l})$ uluses. The lowest indicator of increase was in women of the Tattinsky ulus $(1.01 \pm 0.05 \mathrm{mmol} / \mathrm{l})$.

Table 2. The lipid blood profile in females of the uluses $(\mathrm{M} \pm \mathrm{m})$

\begin{tabular}{|l|l|l|l|l|}
\hline Lipids & Eveno-Bytantaysky & Tattinsky & Verkhoyansky & Verkhnevilyuysky \\
\hline TG & $1.09 \pm 0.08$ & $1.01 \pm 0.05$ & $1.39 \pm 0.3$ & $1.18 \pm 0.08$ \\
\hline Cholesterol & $5.39 \pm 0.11$ & $5.4 \pm 0.09$ & $7.64 \pm 1.47$ & $5.46 \pm 0.1$ \\
\hline HDL & $3.54 \pm 1.95$ & $3.86 \pm 1.8$ & $2.15 \pm 0.67$ & $1.47 \pm 0.04$ \\
\hline LDL & $2.7 \pm 0.07$ & $3.22 \pm 0.08$ & $2.9 \pm 0.11$ & $3.01 \pm 0.09$ \\
\hline VLDL & $0.5 \pm 0.04$ & $0.5 \pm 0.03$ & $0.49 \pm 0.03$ & $0.53 \pm 0.04$ \\
\hline KA & $2.23 \pm 0.1$ & $2.01 \pm 0.08$ & $3.42 \pm 0.11$ & $2.94 \pm 0.13$ \\
\hline
\end{tabular}

This indicator is predominant in men from EvenoBytantaysky ulus $(1.51 \pm 0.33 \mathrm{mmol} / \mathrm{l})$ (Table 3$)$. In general, increased triglycerides often (but not always) lead to cardiovascular disease and the quantitative measure of this risk is highly dependent on the type of lipoproteins in which they are packaged. On the other hand, various causes of glyceridemia (genetic or caused by wrong lifestyle) lead to different ratio profiles of different lipoproteins, and this, in turn, causes different types of complications. Results interpretation of different groups of lipoproteins [3, 4] seems appropriate.

The greatest clinical significance in the analysis is total cholesterol, LDL, HDL. Cholesterol is a fat-like substance that participates in the formation of cell membranes, hormones, and bile acids. It is insoluble in water because of this it binds to proteins, the resulting complex is called lipoprotein.

It should be emphasized that, unlike epidemiological observational studies, not all indicators of lipid metabolism have demonstrated their significant causal relationship with the development of atherosclerotic cardiovascular diseases, primarily coronary heart disease, when using such a sensitive genetic approach as the Mendelian randomization (MR) method. Thus, in the latest and largest such work, Zanetti D, et al. (2020) using MR tools, the pathogenetic role of low-density lipoprotein cholesterol (LDL), triglycerides (TG), lipoprotein (a) and apolipoprotein B ("true risk factors") was confirmed, but, as before, it was not possible to obtain confirmation for high-density lipoprotein cholesterol (HDL), which, according to the authors, are rather a simple biochemical marker, rather than a true risk factor [5].

Cholesterol content is increased in the group of representatives of Tattinsky ulus. In men (5.39 \pm 0.14 $\mathrm{mmol} / \mathrm{l})-34 \%$, in women $(5.4 \pm 0.09 \mathrm{mmol} / \mathrm{l})-41 \%$ of the examined. The cholesterol content exceeds the reference values by 1.5 in women of the Verkhoyansk ulus and is $7.64 \pm 1.47 \mathrm{mmol} / 1$.

Lipoproteins are complex compounds that play a very large role in the functioning of the body. They perform a number of important functions.

HDL decrease was found in the group of men and women - representatives of the Verkhnevilyuy ulus. We 
can assume that this increases the risk of atherosclerosis, since high-density lipoproteins protect the body from the occurrence of atherosclerosis and other similar diseases. Lowering the level of "good" cholesterol is more dangerous condition than it raising. Its increase in the blood level in most cases did not pose a serious threat to human health [3]. These indicators turned out to be slightly higher than normal in the group among Verkhoyansky men and Tattinsky ulus women.

Table 3. The lipid blood profile in men of the uluses $(\mathrm{M} \pm \mathrm{m})$

\begin{tabular}{|l|l|l|l|l|}
\hline Lipids & Eveno-Bytantaysky & Tattinsky & Verkhoyansky & Verkhnevilyuysky \\
\hline TG & $1.51 \pm 0.33$ & $1.09 \pm 0.08$ & $0.87 \pm 0.06$ & $1.06 \pm 0.16$ \\
\hline Cholesterol & $4.86 \pm 0.23$ & $5.39 \pm 0.14$ & $4.93 \pm 0.11$ & $4.91 \pm 0.25$ \\
\hline HDL & $2.03 \pm 0.64$ & $1.64 \pm 0.07$ & $4.55 \pm 3.41$ & $1.41 \pm 0.09$ \\
\hline LDL & $2.8 \pm 0.16$ & $3.24 \pm 0.11$ & $2.69 \pm 0.12$ & $2.59 \pm 0.22$ \\
\hline VLDL & $0.68 \pm 0.15$ & $0.62 \pm 0.11$ & $0.39 \pm 0.03$ & $0.48 \pm 0.07$ \\
\hline KA & $2.69 \pm 0.27$ & $2.38 \pm 0.14$ & $3.46 \pm 0.17$ & $2.73 \pm 0.31$ \\
\hline
\end{tabular}

A combination of high levels of triglycerides, low levels of X-HDL and small dense X-LDL - is usually referred to as a lipid triad, the result of which is diabetic dyslipidemia and atherogenic dyslipidemia. The lipid triad, in turn, is strongly associated with insulin resistance conditions, such as metabolic syndrome, and type 2 diabetes and, in general, is an important risk factor for early atherosclerosis. We did not analyse the classical lipid triad.

The main "vehicle" of cholesterol esters is lowdensity lipoproteins (LDL). LDL has $60-65 \%$ of the total amount (or LDL cholesterol level (LDL + LDL), it does not exceed $3.37 \mathrm{mmol} / \mathrm{l}$ in healthy person. In those patients already affected by atherosclerosis, the values of CS-LDL may increase markedly, which is due to a decrease in antiatherogenic lipoprotein content, that is, this indicator is more informative of atherosclerosis than the level of total cholesterol in the blood [6].

Small dense LDL is formed by the action of a protein that transports cholesterol esters. This protein mediates the exchange of VLDL TG (or chylomicrons) for LDL cholesterol esters, thus leading to the formation of TG-saturated LDL with a low content of cholesterol esters. Subsequently, this particle interacts with hepatic lipase, which breaks down fats to form small dense particles (sd-LDL), which serve as an independent risk factor for cardiovascular events, according to various studies and NCEP III [7].

LDL increase was identified in the group of women of all representatives of uluses. The highest level of low-density lipoproteins occurs in women in the central region of the republic (Tattinsky ulus).

Such indicator as the atherogenicity coefficient, indicates the degree of development of the atherosclerotic process, but it is not the main diagnostic criterion, it is calculated by the formula: $\mathrm{KA}=$ (total cholesterol - cholesterol - HDL): cholesterol - HDL, its normal values range from $2-3$.
It has been established that representatives of the Verkhoyan ulus have a high risk of atherogenicity. This can be explained by the fact that they have a reduced amount of HDL, which removes excess cholesterol, thereby cleaning the vessels. Representatives of the central region remain at moderate risk.

The highest level of low-density lipoproteins occurs in women in the central region of the republic (Tattinsky ulus).

According to the classification of dyslipidemias according to Fredrickson, adopted by the World Health Organization, they are divided into the following types:

Type 1 - indicators are normal or there is a slight increase in cholesterol and triglycerides in the blood. The risk of developing atherosclerosis is unlikely.

Type 2A - the level of triglycerides is normal, cholesterol is elevated. The risk of developing atherosclerosis increases sharply.

Type $2 \mathrm{~B}$ - an increased level of triglycerides and cholesterol in the blood. High risk of developing atherosclerosis.

Type 3 - high levels of triglycerides and cholesterol in the blood. The risk of developing atherosclerosis is significantly increased.

Type 4 - elevated triglyceride levels, cholesterol is more often normal. The risk of developing atherosclerosis is increased.

Type 5-cholesterol is normal or slightly elevated, the level of triglycerides is high. The risk of developing atherosclerosis is low $[8,9]$.

During the comparison of the results obtained, based on the WHO classification of data on the lipid profile of all the examined persons from different regions of the Republic of Sakha (Yakutia), it was shown that $87 \%$ have type $2 \mathrm{~A}$ lipid metabolism disorders, $7 \%$ have type 
2B lipid metabolism disorders and $6 \%$ - type 1 , respectively.

It is alarming that the increase in lipid metabolism is accounted for by representatives of the northern region - Verkhoyansky ulus, both in men and women.

10

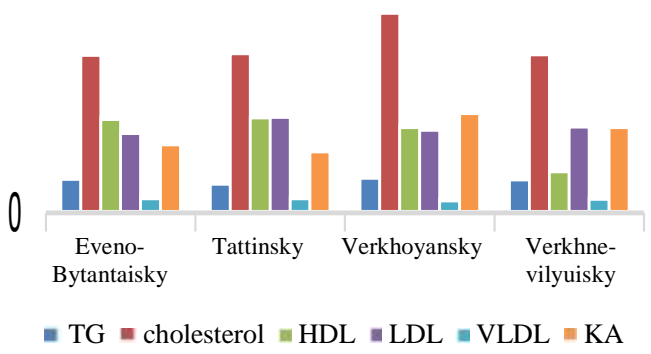

Figure 1. Lipid profile of residents of uluses

These indicators of the lipid profile of northerners should be especially taken into account when carrying out preventive, diagnostic and therapeutic measures for residents of this region.

According to the literature data, in the treatment of cardiovascular diseases, special attention is paid to the indicators of the lipid profile, taking into account the type of dyslipidemia, for the appointment of a certain dose of statins as anti-atherogenic drugs that reduce the risk of serious complications (myocardial infarction, cardiogenic shock, collapse, and others) [10].

Statins are competitive inhibitors of 3-hydroxy-3methylglutaryl CoA reductase - a key enzyme involved in the biosynthesis of cholesterol in the liver. The results of large randomized multicenter studies have convincingly demonstrated the effectiveness of this group of drugs in reducing the level of LDL cholesterol in plasma by $25-50 \%$ from the baseline. It is known that the administration of statins leads to a reduction in the risk of myocardial infarction (MI), stroke and other cardiovascular complications among patients with coronary heart disease; in general, there is a decrease in adverse outcomes of cardiovascular diseases by about $30 \%$. According to the National Cholesterol Education Program (NCEP III - National Cholesterol Education Program III), statins are indicated as a first-line therapy for the secondary prevention of cardiovascular complications (CVD). As for primary prevention, the use of statins (rosuvastatin) is justified in patients with low cardiovascular risk (SSR) and with elevated levels of C-reactive protein (CRP) [11].

At the same time, it will be advisable to establish the type of dyslipedemia to improve the quality of life of patients.

\section{CONCLUSION}

The peculiarities of the shift in the lipid status in our work are changes in the indicators of triglycerides, cholesterol, and low density lipoproteins.

In our study, persistent gender differences in changes in lipid status, in particular in the level of cholesterol, are traced, exceeding the reference values in women of all studied uluses. In men of the Tattinsky ulus, the cholesterol indicator is 5,39 $\pm 0,14 \mathrm{mmol} / \mathrm{l}$, while, like in men from other regions, the cholesterol indicators do not exceed the reference values.

High density lipoproteins in their mass are higher in terms of indicators in women, except for representatives of the Verkhoyansk ulus $(2,15 \pm 0,67 \mathrm{mmol} / \mathrm{l})$, while in men the opposite picture is observed $(4,55 \pm 3,41 \mathrm{mmol} / \mathrm{l})$.

Thus, we can conclude that the lipid profile has its own characteristics depending on the region. The most vulnerable were residents of the central and northern regions of the republic. It is known that in these regions of the Republic of Sakha (Yakutia) the climate is more severe in winter compared to the western region. Adaptation to cold presupposes constant tension of metabolic processes, in particular fatty ones, which leads to significant changes in the lipid profile. Features of the nature of food (fatty varieties of fish, meat, dairy products); the presence of concomitant diseases, lifestyle and characteristics of hormonal status in residents of the central and northern regions of the republic can be complementary risk factors. In this regard, a detailed study of the influence of these factors in further studies remains an urgent issue.

\section{REFERENCES}

[1] E.G. Egorov, G.A. Ponomareva, E.N. Fedorova, Regional economy: theory and practice 14(107) (2009) 16-21.

[2] O.N. Poteryaeva, G.S. Russkykh, N.G. Biushkina et al., Yakutsk Medical J. 2 (2016) 35-37.

[3] A.Yu. Lyudinina, N.N. Potolitsyna, Yu.G. Solonin et al., Human ecology 1 (2014) 13-19.

[4] T.A. Rozhkova, V.N. Titov, V.A. Amelyushkina, V.V. Kukharchuk, Clinical laboratory diagnostics 6 (2017) 330-338.

[5] Yu.I. Grinshtein, V.V. Shabalin, R.R. Ruf et al., Cardiovascular Therapy and Prevention 20(4) (2021) 2865.

[6] Voinov, V.A. Atlas in pathophysiology, Moscow, MIA, 2007.

[7] M. Rizzo, K. Berneis, QJM. 99(1) (2006) 1-14. 
[8] L.N. Komarova, E.R. Lyapunova, A.A. Kotlyarov, E.I. Vitkovskaya, International Journal of Applied and Fundamental Research 1-1 (2016) 32-36.

[9] YY. Byalovsky, V.V. Davydova et al., Lectures on Pathophysiology: a tutorial for studio comrade medical schools, Ryazan, 2018.

[10] D.V. Nebieridze, V.P. Mikhin, T.V. Kamyshova et al., Preventive Medicine 17 (2014) 64-71.

[11] O.M. Drapkina, M.V. Kostyukevich, Diabetes mellitus 15(2) (2012) 77-82. 